\title{
AVALIAÇÃO DE MATERIAIS DIDÁTICOS \\ PROPOSTOS PELO PLANO DE AÇÃO NACIONAL \\ EM AUXÍLIO DA CONSERVAÇÃO DO LOBO-GUARÁ (Chrysocyon brachiurus) ${ }^{1}$
}

\author{
Samara Rached Souza ${ }^{2}$ \\ Simone Maria Ribeiro \\ Rafael Ocanha Lorca Neto \\ Sílvio César Moral Marques \\ Ismail Barra Nova Melo
}

\begin{abstract}
RESUMO
No segundo maior bioma do Brasil, o Cerrado, um importante animal endêmico está em risco de extinção, o lobo-guará (Chrysocyon brachyurus), espécie guarda-chuva. Sua conservação tem impacto direto na proteção de outros animais que ocorrem na mesma área, além de ele mesmo ser importante dispersor de sementes, recebendo o título de "semeador do Cerrado". Visando identificar fragilidades, propor e orientar ações para combater ameaças à fauna, o Plano de Ação Nacional de Espécies Ameaçadas de Extinção do Lobo Guará (PAN-LG) foi criado, mas não se sabe quais ações propostas por ele para aumentar a eficiência na educação da conservação do lobo-guará foram cumpridas. Por isso, os objetivos desse artigo foram: (1) levantar e buscar os materiais didáticos sobre o lobo guará e seu habitat propostos pela ação 1.3 do PAN-LG; (2) verificar quais destes materiais foram realizados e analisá-los qualitativamente; (3) concluir se estes somaram para a conscientização sobre a importância dessa espécie, sendo objetos passíveis de educação ambiental. Para tanto, a metodologia escolhida é utilizada para avaliar situações de difícil mensuração: a cada elemento avaliado, recebe uma pontuação, e o resultado total desse valor enquadrará esse material em uma classificação. Das quatro categorias de materiais propostos (livro para ensino formal, livro infantil, cartilha, vídeo/DVD, jogo educativo), apenas dois foram realizadas, sendo um livro para ensino formal e três vídeos; e os materiais foram classificados, três como razoáveis e um ótimo.
\end{abstract}

Palavras-chave: Preservação. Cerrado. Educação ambiental.

\section{ASSESSMENT OF TEACHING MATERIALS \\ PROPOSED BY THE NATIONAL ACTION PLAN FOR THE CONSERVATION OF THE MANED WOLF (CHRYSOCYON BRACHIURUS)}

\begin{abstract}
\footnotetext{
${ }^{1}$ Como citar esse artigo: SOUZA, S. R. et al. Avaliação de materiais didáticos propostos pelo plano de ação nacional em auxílio da conservação do lobo-guará (Chrysocyon brachiurus). ForScience, Formiga, v. 8, n. 1, e00511, jan./jun. 2020. DOI: 10.29069/forscience.2020v8n1.e511.
}

\footnotetext{
${ }^{2}$ Autor para correspondência: Samara Rached Souza, samyracheed@gmail.com
} 
In the second largest biome of Brazil, the Cerrado, an important endemic animal is in danger of extinction, the maned wolf (Chrysocyon brachyurus), an umbrella species. Its conservation has a direct impact on the protection of other animals occurring in the same area, besides being an important disperser of seeds, receiving the title of "sowing of the Cerrado". In order to identify fragilities, propose and guide actions to combat threats to fauna, the Plano de Ação Nacional de Espécies Ameaçadas de Extinção do Lobo Guará (PAN-LG) was created, but it is not known what actions he proposed to increase efficiency in education of the conservation of the maned-wolf were fulfilled. Therefore, the objectives of this article were: (1) to raise and search for the teaching materials about the maned-wolf and its habitat proposed by action 1.3 of the PAN-LG; (2) to verify which of these materials were carried out and to analyze them qualitatively; (3) conclude if they have added to the awareness about the importance of this species, being objects subject to environmental education. To that end, the methodology used to evaluate situations of difficult measurement: for each element thus evaluated, it received a score, and the total result of this value will frame this material in a classification. Of the four categories of materials proposed (book for formal education, children's book, playbook, video / DVD, educational game), only two were made, one book for formal education and three videos; and the materials were classified, three as reasonable and one great.

Keywords: Preservation. Cerrado. Environmental education.

\section{INTRODUÇÃO}

O Brasil, sozinho, detém $10 \%$ de toda biota terrestre, com estimativas de mais de 1,8 milhões de espécies da fauna e flora distribuídas pelos seus biomas, sendo o Cerrado detentor de cerca de 33\% da diversidade biológica do país (MITTERMEIER et al, 1997; AGUIAR et al, 2004; ICMBIO, 2014). Devido ao fato deste bioma estar sofrendo intensas modificações, muitas espécies, inclusive endêmicas, estão sendo levadas à extinção (KLINK; MACHADO, 2005).

Com o objetivo de adotar ações para prevenir e refrear o risco de extinção de espécies, a Portaria $n^{\circ}$ 43, de 31 de janeiro de 2014 do Ministério do Meio Ambiente instituiu o Programa Nacional de Conservação das Espécies Ameaçadas de Extinção (Pró-Espécies), que utiliza critérios da União Internacional para Conservação da Natureza (IUCN) para categorizar a gravidade em que as espécies se encontram na natureza (Extinta-EX, Extinta na Natureza-EW, Criticamente em Perigo-CR, Em Perigo-EN, Vulnerável-VU, Quase Ameaçada de Extinção-NT, Menos Preocupante-LC, Dados Insuficientes-DD, Não aplicável-NA e Não Avaliada-NE) (BRASIL, 2014; IUCN, 2016) e promover ações para que as espécies com risco de extinção revertam esse quadro, em conformidade com os acordos realizados na Convenção sobre Diversidade Biológica (CDB), um tratado da Organização das Nações Unidas de muita relevância para proteção ambiental (SILVA, 2014). 
O Pró-Espécie utiliza como instrumento os Planos de RUSSO Ação Nacional de Espécies Ameaçadas de Extinção ou do Patrimônio Espeleológico (PAN), que são políticas públicas atuantes como ferramentas de gestão na missão de identificar fragilidades, propor e orientar ações para combater ameaças à fauna (PLANOS DE AÇÃO NACIONAL, 2016). Desde 2004 até 2016, foram realizados 55 Planos Nacionais, abrangendo todos os biomas do Brasil e os grupos taxonômicos de aves, mamíferos, invertebrados terrestres e aquáticos, moluscos, peixes/peixes continentais, répteis e anfíbios (BRASIL, 2014).

Dentre os Planos Nacionais, o do lobo-guará (Chrysocyon brachiurus (ILLIGER, 1815)) destaca-se entre os do Bioma do Cerrado, pois além de estar classificado na categoria “ameaçado de extinção: vulnerável” desde 2010 no Território Nacional (exceto no Paraná, que está classificado de maneira mais preocupante, como "ameaçado de extinção: em perigo") (BRESSAN et al., 2009), também é considerada espécie guarda-chuva, ou seja, sua conservação exerce efeito diretamente em outras espécies com área de mesma ocorrência, tornando-se essenciais programas para sua conservação (GRANIZO et al., 2006).

O Plano de Ação Nacional para Conservação do Lobo Guará (PAN-LG) propõe metas a serem cumpridas através de ações para que a categoria de ameaça na qual o animal se encontra possa sair da categoria de "ameaçada - vulnerável" para "quase ameaçada", e posteriormente, "pouco preocupante". O PAN-LG é composto por 19 metas e 52 ações, sendo foco dessa pesquisa analisar o conteúdo elaborado para solucionar o "Problema 4: capacitação em educação ambiental e pesquisa", proposto pela ação "1.3 desenvolver materiais didáticos sobre o lobo guará e seu habitat e fazer com que sejam distribuídos no ensino formal e informal, além de secretarias de educação e outros órgãos públicos [...]", sendo uma das ações pertinentes a alcançarem a "Meta 1: aumentar a eficiência da educação na conservação do lobo guará".

Esse artigo busca verificar quais materiais propostos pela ação 1.3 foram realizados, e se estão contribuindo para conscientizar a população sobre o lobo-guará.

\section{DESENVOLVIMENTO}

O desenvolvimento da pesquisa se estrutura em três etapas:

1) Levantamento e busca dos materiais propostos pela ação 1.3 do PAN-LG;

2) Análise qualitativa dos materiais didáticos informativos encontrados, seguindo o Quadro 1 como norteador para a avaliação; 
3) Conclusões sobre a qualidade de cada material na conscientização da importância em se conservar a espécies do lobo guará.

Essa metodologia possui o objetivo de avaliar situações de difícil mensuração e, assim, cada elemento de aspecto positivo recebe um valor em pontos, quanto aos mais negativos, menor o valor de pontos atribuído, abordagem esta defendida por GOMES, MELO e VALE (2005). Ao final, quanto maior a pontuação total do material (máximo de 28 pontos), melhor a sua avaliação (Quadros 1 e 2).

\begin{tabular}{|c|c|c|c|c|c|}
\hline \multicolumn{5}{|c|}{ Identificação do Material } \\
\hline Material/Forma de apresentação \\
\hline Qual a aplicação desse material? \\
\hline Fonte Avaliação & $\begin{array}{c}\text { Ótimo } \\
(4)\end{array}$ & $\begin{array}{c}\text { Bom } \\
(3)\end{array}$ & $\begin{array}{c}\text { Razoável } \\
(2)\end{array}$ & $\begin{array}{c}\text { Ruim } \\
\text { (1) }\end{array}$ & $\begin{array}{c}\text { Péssimo } \\
\text { (0) }\end{array}$ \\
\hline $\begin{array}{c}\text { Existem recursos visuais (no caso de material } \\
\text { impresso) ou de texto (no caso de vídeo)? } \\
\text { Estes e outros elementos são relevantes ao } \\
\text { desenvolvimento do texto? }\end{array}$ & & & & & \\
\hline $\begin{array}{c}\text { Existem dados? } \\
\text { Eles se apresentam de fácil interpretação? }\end{array}$ & & & & & \\
\hline $\begin{array}{c}\text { O material induz o público alvo a buscar outras fontes } \\
\text { de informação? }\end{array}$ & & & & & \\
\hline $\begin{array}{c}\text { Os conteúdos com relação ao animal estão corretos? } \\
\text { Outras informações da temática de ciências biológicas } \\
\text { e áreas correlatas foram utilizadas de maneira clara e } \\
\text { atualizadas? }\end{array}$ & & & & & \\
\hline $\begin{array}{c}\text { Foram desmistificados tradições sobre a espécie? Ou } \\
\text { abordados outros conceitos que ameaçam a } \\
\text { sobrevivência da espécie? }\end{array}$ & & & & & \\
\hline A importância ecológica do lobo guará foi descrita? & & & & & \\
\hline
\end{tabular}

Quadro 1 - Questões norteadoras para avaliação sobre efetividade de materiais na conscientização da conservação do Lobo Guará e contagem de pontos.

Fonte: Autores, adaptado de Gomes et al. (2005).

A ficha contém as seguintes informações que foram preenchidas: de qual material a avaliação se refere e qual a forma de apresentação da mesma, por exemplo, DVD, cartilha, vídeo, livro, capítulo, jogo, dentre outros; qual a aplicação deste material, se é distribuição de material físico, conteúdo online, para trabalho em escolas, dentre outros; e qual a fonte na qual o material pode ser acessado.

Após identificação do material didático analisado, e foi necessário preenchimento de questões norteadoras para avaliação, sendo que cada resposta recebeu uma pontuação: 
1) Observar se existem recursos visuais e como estes ou outros elementos informativos estão dispostos com relação ao texto, pois estes elementos são suporte para as informações contidas no material, tornando as informações claras, estimulando a compreensão e a interação dos leitores com o texto (VASCONCELOS; SOUTO, 2003). Foi verificado se existem imagens autoexplicativas (esquemas) que auxiliem no entendimento do texto ou da narração; se as figuras subsidiam a retenção do que é informado ao leitor ilustrando o que está sendo descrito; se são apenas de caráter ilustrativo; se transmitem uma informação superficial e até mesmo errônea sobre o assunto; ou se estão desconexas ao tema tratado (SANTOS; OLIVEIRA, 2012);

2) Caso existam dados, identificar se são de fácil interpretação, como no caso de tabelas ou gráficos, para que dados que permeiam a temática possam ser apresentados ao público de maneira clara;

3) Observar se o material induz o público a buscar informações além do disponibilizado, indicando locais os quais possam ser acessados para mais informações sobre o assunto, criando questionamentos sem resposta para instigar o público a pesquisar sobre o lobo guará, ou similares;

4) Verificar se o conteúdo acerca da biologia do animal está correto (PAULA; GAMBARINI, 2013);

5) Verificar se eventuais informações da temática de ciências biológicas e áreas correlatas são claras e assertivas, tendo em vista que é difícil abordar alguns aspectos técnicos e/ou biológicos com o público leigo sem estudo prévio, porém de fundamental importância para o público querer contribuir na conservação da espécie;

6) Avaliar se foram desmistificados tradições, ou informados de ocorrências que possam ameaçar a sobrevivência da espécie;

7) Verificar a importância ecológica do lobo guará como agente dispersor e espécie topo de cadeia alimentar foi informada.

\begin{tabular}{|c|c|}
\hline Nota & Pontuação Final \\
\hline Ótimo & Igual ou acima de 25 pontos \\
\hline Bom & Entre 24 a 19 pontos \\
\hline Razoável & 18 a 13 pontos \\
\hline Ruim & 12 a 07 pontos \\
\hline Péssimo & Igual ou abaixo de 06 pontos \\
\hline
\end{tabular}

Quadro 2 - Pontuação final para gerar nota de cada material didático. Fonte: Autores, adaptado de Gomes et al. (2005). 


\section{DISCUSSÃO DOS RESULTADOS}

O PAN-LG no Grupo de Trabalho "Educação ambiental, aspectos sociais e alternativas econômicas", constituído por 10 integrantes que compõe o elenco de Universidades, Instituições, buscaram solucionar o "Problema 4: capacitação em educação ambiental e pesquisa", com seis ações, sendo uma delas a proposta da ação "1.3 desenvolver materiais didáticos sobre o lobo guará e seu habitat e fazer com que sejam distribuídos no ensino formal e informal, além de secretarias de educação e outros órgãos públicos [...]", pertinente a alcançar um dos tópicos da "Meta 1: aumentar a eficiência da educação na conservação do lobo guará".

Dessa maneira, a “Ação 1.3" definiu desenvolver: um livro/capítulo para o ensino formal sobre o lobo guará e seu habitat; um livro de história infantil sobre o lobo guará e seu habitat; uma cartilha educativa para as comunidades, instituições zoológicas mantenedoras, áreas protegidas; Vídeos/DVD sobre o lobo guará e seu habitat; além de Jogos educativos.

O cumprimento dessa ação teve como responsáveis profissionais representantes do Instituto Brasileiro do Meio Ambiente e dos Recursos Naturais - IBAMA, Fundação ZooBotânica de Belo Horizonte, Sociedade de Zoológicos e Aquários do Brasil, Instituto Chico Mendes de Conservação da Biodiversidade - ICMBio/ Centro Nacional de Pesquisa para a Conservação de Predadores Naturais - CENAP, Companhia Brasileira de Metalurgia e Mineração, Jardim Zoológico de La Ciudad de Buenos Aires e do Nacional Zoo Conservation and Research Center, e com o apoio de colaboradores que sejam profissionais do ensino formal, com prazo para término e aplicação até 2015.

O livro indicado para o ensino formal foi o "Vivendo no Cerrado e aprendendo com ele”, do autor Marcelo Bizerril, já existente antes da elaboração do PAN-LG, este que está sendo distribuído desde 2006 pelo Ministério da Educação (MEC) nas escolas da rede pública de ensino fundamental pelo Programa Nacional do Livro Paradidático (PNLD-SP). Destaca-se que o livro bem reforçando o ensino de ciências e geografia, e que foi mantido pelos responsáveis para cumprir a meta proposta, pois atende as necessidades levantadas pelo PANLB (BIZERRIL, 2009; BRASIL, 2016).

Três vídeos foram elaborados e estão disponíveis na web, cujos títulos são "Programa para a Conservação do Lobo Guará - Lobos da Canastra” (2015), realizados em parceria pelo Pró-carnívoros e CENAP/ICMBio; o vídeo "Projeto Sou Amigo do Lobo" (2015), com coordenação de Rogério Cunha de Paula, ambos publicados no canal do Youtube do Projeto 
"Sou Amigo do Lobo"; e o "Conheça o lobo guará, símbolo do Cerrado" (2015), publicado no canal do ICMBio, em parceria com o Banco Mundial, MMA, ICMBio, Global Environment Facility (GEF), e Fundo Brasileiro para a Biodiversidade (FunBio).

O DVD e os jogos educativos propostos não foram elaborados pelos responsáveis das ações pela falta de recursos financeiros; a cartilha foi iniciada com o auxílio de parcerias, mas precisou ser interrompida pelo mesmo motivo (PAULA, 2016), e a citada no PAN-LG “AZA Species Survival Plan (SSP) Maned Wolf” não está disponível. O livro infantil não foi finalizado, pois como indicado no PAN-LG, o obstáculo seria o de obter recursos financeiros para produção do material, o que atrasou a elaboração do mesmo. Porém, o mesmo está em andamento em parceria com o Instituto Maurício de Sousa (PAULA, 2016).

Segundo Garcia (2016), outros materiais que possuem enfoque na conservação do lobo guará foram encontrados (quatro cartilhas, dois jogos educativos, um DVD produzido pela Companhia Energética de Minas Gerais - CEMIG e um caderno de atividades), mas não serão analisados nesta pesquisa por não abarcar o foco proposto, que é o de avaliar especificamente as ações postuladas pelo PAN-LB a serem realizadas pelos responsáveis ou materiais previamente apontados.

O vídeo "Conheça o Lobo Guará, símbolo do Cerrado", primeiro material analisado, possui duração de 8:03 minutos, está disponível no canal do ICMBio da plataforma do YouTube, e possui 206.008 visualizações até setembro de 2019 (Quadro 3).

\begin{tabular}{|c|c|c|c|c|c|c|}
\hline \multicolumn{7}{|c|}{ Identificação do Material } \\
\hline Material/Forma de apresentação & \multicolumn{6}{|c|}{ Conheça o Lobo Guará, o símbolo do Cerrado - Vídeo online } \\
\hline Qual a aplicação desse material? & \multicolumn{6}{|c|}{ Diverso } \\
\hline Fonte & \multicolumn{6}{|c|}{ https://www.youtube.com/watch?v=CwIshsHrT04\&spfreload=10 } \\
\hline \multirow{2}{*}{\multicolumn{2}{|c|}{ Avaliação }} & \multicolumn{5}{|c|}{ Pontuação } \\
\hline & & $\begin{array}{l}\text { Óti } \\
\text { (4) }\end{array}$ & $\begin{array}{l}\text { Bom } \\
\text { (3) }\end{array}$ & $\begin{array}{c}\mathrm{Raz} \\
\text { (2) }\end{array}$ & $\begin{array}{l}\text { Rui } \\
\text { (1) }\end{array}$ & $\begin{array}{l}\text { Pés } \\
\text { (0) }\end{array}$ \\
\hline \multicolumn{2}{|c|}{$\begin{array}{l}\text { Existem recursos visuais (no caso de material impresso) ou de texto (no } \\
\text { caso de vídeo)? Estes e outros elementos são relevantes ao } \\
\text { desenvolvimento do texto / narração? }\end{array}$} & & $\mathrm{X}$ & & & \\
\hline \multicolumn{2}{|c|}{ Existem dados? Eles se apresentam de fácil interpretação? } & & $\mathrm{X}$ & & & \\
\hline \multicolumn{2}{|c|}{ O material induz o público alvo a buscar outras fontes de informação? } & $\mathrm{X}$ & & & & \\
\hline \multicolumn{2}{|c|}{ Os conteúdos com relação ao animal estão corretos? } & $\mathrm{X}$ & & & & \\
\hline \multicolumn{2}{|c|}{$\begin{array}{c}\text { Outras informações da temática de ciências biológicas e áreas correlatas } \\
\text { foram utilizadas de maneira clara e atualizadas? }\end{array}$} & & $\mathrm{X}$ & & & \\
\hline \multicolumn{2}{|c|}{$\begin{array}{c}\text { Foram desmistificadas tradições sobre a espécie? Ou abordados } \\
\text { conceitos que ameaçam a sobrevivência da espécie? }\end{array}$} & & & & $\mathrm{X}$ & \\
\hline \multicolumn{2}{|c|}{ A importância ecológica do lobo guará foi descrita? } & & & & & $\mathrm{X}$ \\
\hline
\end{tabular}

Quadro 3 - Descrição do material analisado proposto pelo PAN Lobo Guará (vídeo) com os parâmetros de avaliação e sua respectiva pontuação.

Fonte: Autores. 
O material didático previsto pelo PAN Lobo Guará obteve um resultado de 18 pontos, sendo classificado como Razoável.

Vídeos são cada vez mais utilizados como recursos pedagógicos, sendo uma variedade dentro dos múltiplos tipos de aprendizagem, sendo que muitas pessoas aprendem melhor quando submetidas a estímulos visuais e sonoros quando comparado com a educação tradicional. O YouTube, lançado em 2005, pode não demonstrar apelo pedagógico, mas é utilizado com muito sucesso quando o assunto é educação e velocidade de divulgação (MATTAR, 2009).

Elementos informativos foram empregados, como por exemplo, o nome "Lobo Guará" aparece no início do vídeo, e quando este foi apresentado, no canto inferior esquerdo foi apresentado o seu nome científico Chrysocyon brachiurus. Fizeram parte do vídeo diretamente (ou seja, apareceram em imagem), três participantes, e foi existente o uso de elementos informativos, pois os contribuintes foram apresentados (nome e atuação profissional de forma textual). Existe a possibilidade de legenda no vídeo, gerada automaticamente pelo YouTube, porém aparece incompleta ou gerada com palavras trocadas, por exemplo, invés de "solitário" a legenda foi gerada como "solidário"; e não existe a comunicação em libras no canto inferior direito do vídeo como elemento visual para promover o entendimento de pessoas deficientes auditivas acerca do tema.

Durante todo vídeo existe uma trilha sonora instrumental, que acaba fazendo uma "brincadeira" com os elementos de imagem do vídeo, por exemplo, quando o lobo guará é filmado dando seu típico "mergulho" para predar algum pequeno animal, a trilha sonora acompanha seus pulos com nota musical aguda, sendo considerado elemento relevante para desenvolvimento do material, e que prende a atenção do espectador nos detalhes. As imagens e filmagens apresentadas no vídeo auxiliam na retenção do que é informado ao leitor, pois ilustram o que está sendo descrito pelo narrador naquele momento. Por exemplo, o narrador começa o vídeo dizendo que é preciso olhos atentos para descobrir a beleza da paisagem, enquanto várias imagens do bioma aparecem, e cita que as belezas estão nos detalhes, (mostrando flores em zoom) e na imensidão (mostrando o bioma de forma ampla). Vídeos interativos e com a presença de animações obtém melhores aceitações por parte do público, e fazem com que as pessoas fiquem mais atentas ao que está sendo dito (LIMA et al., 2012).

Os dados informativos além de narrados, também apareceram na forma textual. Por exemplo, em determinado momento do vídeo, o narrador cita que o Brasil abriga $13 \%$ de todas as espécies do planeta, sendo 100 mil invertebrados e 9.228 vertebrados, o que apareceu 
de maneira escrita, porém, gerou-se dúvida: 100 mil espécimes ou espécies de invertebrados? E do que se trata o número de vertebrados citados? Quais outras colocações poderiam ser feitas? Existem divergências na quantidade de espécies contabilizadas, porém os dados citados no vídeo não são condizentes com as estimativas utilizadas pelo ICMBio e disponíveis na sua página online (http://www.icmbio.gov.br/portal/faunabrasileira/). Imagina-se que as estimativas foram atualizadas, pois o vídeo é de 2015. O mesmo aconteceu com relação ao próximo item verificado.

O material induz o público a buscar outras fontes de informação. Ao final do vídeo, além dos créditos, aparece a seguinte mensagem "Para saber mais, visite www.icmbio.gov.br/faunabrasileira e Facebook/icmbio", sendo que há um erro no primeiro endereço sugerido, pois ele foi testado, e verificou-se que para acessar a aba de "fauna brasileira" no portal do ICMBio, o endereço correto seria http://www.icmbio.gov.br/portal/faunabrasileira/, mas o vídeo é de 2015, e este poderia estar correto e foi modificado. A busca por demais informações sobre o assunto faz parte do método construtivista de ensino, pois quem está aprendendo se torna ativo no processo de ensino; mas também pode ser recebido com desinteresse, pois estamos acostumados a receber conteúdo de forma mecânica, resultado de uma educação de metodologia tradicional (KRUGER et al., 2013).

No vídeo, os itens anteriores de "dados informativos" e "outras fontes de informação" foram considerados desatualizados, o que é algo considerável dentro do mundo da web, e espera-se prudência por parte do público (que faz parte dessa tecnologia, já que está assistindo conteúdo online) para também considerar essa hipótese.

O conteúdo abordado acerca do animal está correto, o vídeo explica sobre o Parque da Serra da Canastra, na qual podemos encontrar grande número de lobos, pois há território e alimentos suficientes para a espécie de lobo, além de interações sem interferência humana. Parte importante do vídeo explica que o Governo Federal estabeleceu uma estratégia para mobilizar a sociedade a salvar animais com risco de extinção, esta que é iniciada através do PAN, elaborado por especialistas da área, que verificam seu tamanho populacional, localização, ambiente e avaliam as ameaças à sua sobrevivência, podendo assim, criar estratégias para preservá-los.

O vídeo explica que proteger o lobo é muito importante, porque o animal ocupa uma grande área, e para protegê-lo é necessário proteger a área na qual ele vive, resultando no beneficiamento de todas as espécies do bioma. $\mathrm{O}$ vídeo também aborda uma grande ameaça à 
sobrevivência da espécie, a do lobo comer galinhas de proprietários rurais, e que o Projeto do Instituto Pró Carnívoros diminui os conflitos da população humana com eles, ajudando os proprietários a construir galinheiros domésticos, o que aumenta a produtividade dos criadores e protege as galinhas de serem predadas pelos lobos e outros animais silvestres. Outros problemas que ameaçam a sobrevivência da espécie não foram abordados. Também não foi abordada a importância ecológica da espécie.

O segundo material didático analisado, o vídeo "Projeto Sou Amigo do Lobo", possui duração de 3:05 minutos, e está disponível no canal Projeto Amigo do Lobo da plataforma do YouTube, e que possui 36.158 visualizações até setembro de 2019 (Quadro 4).

\begin{tabular}{|c|c|c|c|c|c|c|}
\hline \multicolumn{7}{|c|}{ Identificação do Material } \\
\hline Material/Forma de apresentação & \multicolumn{6}{|c|}{ Projeto Sou Amigo do Lobo - Vídeo online } \\
\hline Qual a aplicação desse material? & \multicolumn{6}{|c|}{ Diverso } \\
\hline Fonte & \multicolumn{6}{|c|}{ https://www.youtube.com/watch?v=xCjjblBKczI } \\
\hline \multirow{2}{*}{\multicolumn{2}{|c|}{ Avaliação }} & \multicolumn{5}{|c|}{ Pontuação } \\
\hline & & $\begin{array}{l}\text { Óti } \\
(4)\end{array}$ & $\begin{array}{c}\text { Bom } \\
(3)\end{array}$ & $\begin{array}{c}\mathrm{Raz} \\
(2)\end{array}$ & $\begin{array}{c}\text { Rui } \\
(1)\end{array}$ & $\begin{array}{l}\text { Pés } \\
(0)\end{array}$ \\
\hline \multicolumn{2}{|c|}{$\begin{array}{c}\text { Existem recursos visuais (no caso de material impresso) ou de texto (no caso } \\
\text { de vídeo)? Existem outros recursos? Se sim, são relevantes ao } \\
\text { desenvolvimento do texto / narração? }\end{array}$} & $\mathrm{X}$ & & & & \\
\hline \multicolumn{2}{|c|}{ Existem dados? Eles se apresentam de fácil interpretação? } & & & & & $\mathrm{X}$ \\
\hline \multicolumn{2}{|c|}{ O material induz o público alvo a buscar outras fontes de informação? } & & & & & $\mathrm{X}$ \\
\hline \multicolumn{2}{|c|}{ Os conteúdos com relação ao animal estão corretos? } & $\mathrm{X}$ & & & & \\
\hline \multicolumn{2}{|c|}{$\begin{array}{c}\text { Outras informações da temática de ciências biológicas e áreas correlatas } \\
\text { foram utilizadas de maneira clara e atualizadas? }\end{array}$} & & & $\mathrm{X}$ & & \\
\hline \multicolumn{2}{|c|}{$\begin{array}{c}\text { Foram desmistificados tradições sobre a espécie? Ou abordados outros } \\
\text { conceitos que ameaçam a sobrevivência da espécie? }\end{array}$} & & $\mathrm{X}$ & & & \\
\hline \multicolumn{2}{|c|}{ A importância ecológica do lobo guará foi descrita? } & $\mathrm{X}$ & & & & \\
\hline
\end{tabular}

Quadro 4 - Descrição do material analisado proposto pelo PAN Lobo Guará (vídeo) com os parâmetros de avaliação e sua respectiva pontuação.

Fonte: Autores.

O material didático previsto pelo PAN Lobo Guará obteve um resultado de 17 pontos, sendo classificado como Razoável.

Não existem recursos de texto no vídeo em questão, e isso deve se dar ao fato de que o objetivo do vídeo é o de abordar de forma clara o papel que o animal desempenha no ecossistema, sem dar maior importância para dados específicos/científicos e dados quantitativos, alcançando uma diversa faixa etária, e isso é evidente quando a narração se inicia. A narradora é uma criança, e transmite informações ao público com uma linguagem oral formal, e com um texto narrado bem elaborado, pois se diz muito falando pouco e nos 
levando a uma reflexão, o que pode ser percebido nos trechos "anda sozinho pelo Cerrado, e a cada passo dele com suas pernas longas movimenta o mundo inteiro", "o lobo anda sozinho mas sem saber carrega um peso muito grande: a missão de apresentar o Cerrado a quem não conhece", "a resistência das matas, o vermelho do entardecer, o lobo carrega com ele". Ou seja, essa abordagem inusitada do vídeo pode ser considerada um recurso, pois auxilia no aumento da atenção e na maneira com que o telespectador irá incorporar as informações que a mensagem busca transmitir, sendo uma estratégia de assimilação eficiente unificando estímulos visuais e auditivos inusitados (LIMA et al., 2002).

Não existem dados que possam ser apresentados em forma de gráfico ou outros, pois os dados apresentados não são quantitativos, e o material não induz o público alvo a buscar outras fontes de informação acerca do animal.

Em alguns trechos fazem menção a suas pernas longas, sua coloração avermelhada, que ele se alimenta de frutas (como a da lobeira), semeia as sementes, e também que caça animais a luz do luar (fazendo menção ao fato dele ser um animal de hábitos crepusculares), e que ele é um animal solitário "porém não anda sozinho" (fazendo alusão de que nós o estamos apoiando).

Foram encontrados trechos que correlacionam informações da área de ciências biológicas com o lobo, mas que foram apenas abordadas de maneira superficial (citando a diversidade de paisagens as quais o lobo é permeável, a importância que o animal desempenha como semeador e como isso reflete no bioma e nos animais que ali também vivem, etc.).

Um dos fatores que ameaça a sobrevivência da espécie, a do lobo se alimentar de animais de criação e que gera conflito entre animal e produtor, ocorreu de maneira muito sutil, como podemos ver no trecho: "Era uma vez um lobo. Muita gente pensa que ele é mau: só come galinha, pato, marreco, mas nada disso é verdade. A verdade eu já sei, o lobo não é mau, ele é guará", que abre o início da narração do vídeo, e "nada de 3 porquinhos ou chapeuzinho vermelho", fazendo menção às historinhas infantis as quais mostram o lobo sempre como vilão.

A importância ecológica da espécie teve ênfase nesse material, pois em vários momentos o vídeo demonstra o quanto a espécie é importante para nós, para outros animais, e para o bioma, como pode ser exemplificado no trecho: "por onde passa o lobo, novas árvores vão brotando. Por onde passa o lobo a natureza ganha novas chances de sobreviver: pássaros encontram galhos para fazerem novos ninhos, insetos encontram cantinhos para se 
multiplicar, o tamanduá tem sombra para descansar", "se o lobo não desistiu de cuidar do Cerrado... de fazer esse mundo melhor... por que você vai desistir?".

O vídeo "Programa para a Conservação do Lobo Guará - Lobos da Canastra", possui duração de 8:03 minutos, e está disponível no canal Projeto Amigo do Lobo da plataforma do YouTube, e que possui 4.159 visualizações até setembro de 2019 (Quadro 5).

\begin{tabular}{|c|c|c|c|c|c|c|}
\hline \multicolumn{7}{|c|}{ Identificação do Material } \\
\hline Material/Forma de apresentação & \multicolumn{6}{|c|}{$\begin{array}{l}\text { Programa para a Conservação do Lobo Guará - Lobos da Canastra - Vídeo } \\
\text { online }\end{array}$} \\
\hline Qual a aplicação desse material? & \multicolumn{6}{|c|}{ Diverso } \\
\hline Fonte & \multicolumn{6}{|c|}{ https://www.youtube.com/watch?v=JgUqBB0AUcw } \\
\hline \multirow{2}{*}{\multicolumn{2}{|c|}{ Avaliação }} & \multicolumn{5}{|c|}{ Pontuação } \\
\hline & & $\begin{array}{l}\text { Óti } \\
\text { (4) }\end{array}$ & $\begin{array}{c}\text { Bom } \\
(3)\end{array}$ & $\begin{array}{l}\text { Méd } \\
(2)\end{array}$ & $\begin{array}{l}\text { Rui } \\
\text { (1) }\end{array}$ & $\begin{array}{l}\text { Pés } \\
(0)\end{array}$ \\
\hline \multicolumn{2}{|c|}{$\begin{array}{c}\text { caso de vídeo)? Estes e outros elementos são relevantes ao } \\
\text { desenvolvimento do texto / narração? }\end{array}$} & & & & $\mathrm{X}$ & \\
\hline \multicolumn{2}{|c|}{ Existem dados? Eles se apresentam de fácil interpretação? } & & & & $\mathrm{X}$ & \\
\hline \multicolumn{2}{|c|}{ O material induz o público alvo a buscar outras fontes de informação? } & & & $\mathrm{X}$ & & \\
\hline \multicolumn{2}{|c|}{ Os conteúdos com relação ao animal estão corretos? } & & $\mathrm{X}$ & & & \\
\hline \multicolumn{2}{|c|}{$\begin{array}{c}\text { Outras informações da temática de ciências biológicas e áreas correlatas } \\
\text { foram utilizadas de maneira clara e atualizadas? }\end{array}$} & & $\mathrm{X}$ & & & \\
\hline \multicolumn{2}{|c|}{$\begin{array}{c}\text { Foram desmistificados tradições sobre a espécie? Ou abordados outros } \\
\text { conceitos que ameaçam a sobrevivência da espécie? }\end{array}$} & $\mathrm{X}$ & & & & \\
\hline \multicolumn{2}{|c|}{ A importância ecológica do lobo guará foi descrita? } & $\mathrm{X}$ & & & & \\
\hline
\end{tabular}

Quadro 5 - Descrição do material analisado proposto pelo PAN Lobo Guará (vídeo) com os parâmetros de avaliação e sua respectiva pontuação.

Fonte: Autores.

O material didático previsto pelo PAN Lobo Guará obteve um resultado de 18 pontos, sendo classificado como Razoável.

Não foram encontrados recursos de texto que pudessem somar na compreensão da narração, mesmo que ao longo do vídeo vários dados tenham sido citados, mas as imagens são compatíveis com o áudio, o que é coerente para que a informação possa atingir a compreensão do telespectador, em especial nesse vídeo, que informa mais detalhadamente processos para conservação do lobo do que os outros vídeos analisados. A narração conta com dados numéricos fornecidos, mas só são apresentados através do som, não incluindo legendas, libras, informações complementares, gráficos ou que apareçam escritos no vídeo para ajudar na retenção da informação. Tanto neste quanto nos outros vídeos, cabe lembrar que além de auxiliar na compreensão do que se é narrado, seria interessante o uso de legendas, pois facilitaria o acesso de deficientes auditivos à mídia televisiva, sendo um direito e maximizando a gama de pessoas que teriam acesso à conscientização do lobo-guará (FARIA; 
SILVA, 2016), tendo em vista que a legenda automática da plataforma a qual o vídeo está inserido é passível de muitos erros, atrapalhando o entendimento do mesmo.

Mesmo não estando explícito, a vídeo faz um tour por dentro do Projeto Lobos da Canastra, o que pode induzir o público alvo a buscar outras fontes sobre o assunto, vez que são suficientes os elementos informativos apresentados para que o telespectador possa pesquisar por si caso se interesse.

Os conteúdos com relação ao animal foram superficialmente descritos, porém corretamente; e outras informações que permeiam as ciências biológicas também foram pouco citadas, mas quando sim, de maneira compreensível.

Dentre todos os materiais analisados, este foi o que mais abordou as ameaças que afetam a sobrevivência do lobo, "redução de áreas populacionais, atropelamentos, conflitos com fazendeiros, doenças de animais domésticos canídeos", e ainda discorre sobre cada ameaça e quais ações o Projeto Lobos da Canastra realiza para minimizá-los (estudo da relação da espécie com o ambiente e a comunidade, coleira com transmissor para acompanhar os animais e quantificar o impacto da degradação ambiental na espécie, vacinação de animais de estimação da região para diminuir disseminação de zoonoses entre canídeos, sistema de galinheiros, ações educativas em escolas, cinema, distribuição de livros e cartilhas). A importância ecológica do lobo-guará foi bem citada de maneira indireta ao apresentarem as medidas que o Projeto Lobos da Canastra realiza, pois, todas as ações são voltadas justamente pela grande importância que essa espécie desempenha.

O último material analisado, o Livro "Vivendo no Cerrado - e aprendendo com ele", pode ter sua pontuação observada no Quadro 6.

\begin{tabular}{|c|c|c|c|c|c|c|}
\hline \multicolumn{7}{|c|}{ Identificação do Material } \\
\hline Material/Forma de apresentação & \multicolumn{6}{|l|}{ Livro } \\
\hline Qual a aplicação desse material? & \multicolumn{6}{|c|}{$\begin{array}{l}\text { Distribuição do livro pelo MEC nas escolas da rede pública pelo PNLD-SP e } \\
\text { compra do mesmo através de livrarias }\end{array}$} \\
\hline Fonte & \multicolumn{6}{|c|}{$\begin{array}{l}\text { BIZERRIL, Marcelo. 2009. Vivendo no Cerrado - e aprendendo com ele. São } \\
\text { Paulo: Saraiva, } 1^{\mathrm{a}} \text { ed., } 6^{\mathrm{a}} \text { tiragem. } 79 \mathrm{p} .\end{array}$} \\
\hline \multirow{2}{*}{\multicolumn{2}{|c|}{ Avaliação }} & \multicolumn{5}{|c|}{ Pontuação } \\
\hline & & $\begin{array}{l}\text { Óti } \\
\text { (4) }\end{array}$ & $\begin{array}{c}\text { Bom } \\
(3)\end{array}$ & $\begin{array}{c}\text { Méd } \\
(2)\end{array}$ & $\begin{array}{c}\text { Rui } \\
\text { (1) }\end{array}$ & $\begin{array}{l}\text { Pés } \\
\text { (0) }\end{array}$ \\
\hline \multicolumn{2}{|c|}{$\begin{array}{l}\text { Existem recursos visuais (no caso de material impresso) ou de texto (no } \\
\text { caso de vídeo)? Estes e outros elementos são relevantes ao } \\
\text { desenvolvimento do texto / narração? }\end{array}$} & $\mathrm{X}$ & & & & \\
\hline \multicolumn{2}{|c|}{ Existem dados? Eles se apresentam de fácil interpretação? } & $\mathrm{X}$ & & & & \\
\hline \multicolumn{2}{|c|}{ O material induz o público alvo a buscar outras fontes de informação? } & $\mathrm{X}$ & & & & \\
\hline \multicolumn{2}{|c|}{ Os conteúdos com relação ao animal estão corretos? } & & $\mathrm{X}$ & & & \\
\hline
\end{tabular}




\begin{tabular}{|c|c|c|c|c|c|}
\hline $\begin{array}{c}\text { Outras informações da temática de ciências biológicas e áreas correlatas } \\
\text { foram utilizadas de maneira clara e atualizadas? }\end{array}$ & $\mathrm{X}$ & & & \\
\hline $\begin{array}{c}\text { Foram desmistificados tradições sobre a espécie? Ou abordados outros } \\
\text { conceitos que ameaçam a sobrevivência da espécie? }\end{array}$ & & $\mathrm{X}$ & & & \\
\hline A importância ecológica do lobo guará foi descrita? & & $\mathrm{X}$ & & & \\
\hline
\end{tabular}

Quadro 6 - Descrição do material analisado proposto pelo PAN Lobo Guará (livro) com os parâmetros de avaliação e sua respectiva pontuação

Fonte: Autores.

“O Livro previsto pelo PAN Lobo Guará obteve um resultado de 25 pontos, sendo classificado como Ótimo".

Foram identificados recursos visuais logo no sumário (p. 5), o qual cada capítulo é representado por uma imagem, por exemplo, o capítulo "O Ambiente" é ilustrado com uma imagem do Canion do Parque Estadual das Nascentes do Rio Taquari, no Mato Grosso do Sul.

Todo texto é complementado com imagens sobre o que está sendo discutido, o que ilustra e ajuda na compreensão por parte do leitor sobre o tema tratado. Por exemplo, quando se explica os fatores que fazem com que o Cerrado seja adaptado ao fogo, citam que um dos motivos são as grossas cascas das árvores que conferem resistência a elas, e ao lado, uma imagem do tronco do tamboril, seguido pelo seu nome científico, árvore que apresente uma grossa camada de casca; e mostram também duas imagens que ilustram o assunto: uma área de Cerrado recém queimada e outra área rebrotando após passagem da queimada.

Outro elemento informativo são quadros azuis que exercem função de "dicionário rápido". Ao longo do texto, algumas palavras estão com fonte na cor azul, e as mesmas podem ser encontradas nesses quadros com sua respectiva explicação, o que é muito útil no entendimento do significado de palavras específicas. Por exemplo, no trecho " $\mathrm{O}$ desmatamento do Cerrado apresenta múltiplas causas, dentre elas, podemos destacar o garimpo, a implantação de monoculturas, o plantio de espécies exóticas, como pinheiros e eucaliptos [...]" (p.51), na qual o termo "espécies exóticas" se apresenta em um quadro azul na mesma página, com a explicação: “espécies presentes em uma determinada área geográfica da qual não é originária”.

O material possui dados que foram apresentados de diversas maneiras, identificados através do uso de 04 mapas, 01 esquema, 05 tabelas e 02 gráficos, além de estarem descritos ao longo dos textos. Essas apresentações dos dados foram consideradas todas de fácil interpretação: as cores dos mapas bem distintas, os gráficos apresentados em barras e de maneira simples, o esquema foi adaptado e possui clareza de informações, as tabelas com 
colunas e tabelas bem divididas e sem dados sobrepostos, todos de interpretação indutiva, cumprindo com o objetivo proposto.

O material possui forte apelo para que o público alvo busque outras fontes de informação, que pode ser identificado em quadros coloridos espalhados pelas páginas propondo algumas reflexões. O primeiro quadro é intitulado pelo autor de "Para Refletir e Debater", e dentro dele estão algumas perguntas referentes ao capítulo, como por exemplo, o capítulo "Os impactos", no subtítulo "Impacto das queimadas", possui esse quadro com a questão: "Se o Cerrado apresenta adaptações para conviver com o fogo, porque queimá-lo gera problemas?", fazendo com que o leitor reflita sobre o texto disponível no livro e lido, e também possa buscar outras fontes para resolver as questões estabelecidas.

Um segundo quadro, o "Pesquise", traz perguntas as quais não podem ser encontradas no livro, e que fazem com que o leitor tenha que aplicar o que aprendeu em alguma situação da sua vida cotidiana, o aproximando do assunto. Por exemplo, o "Pesquise" encontrado na página 51: "Quais as principais espécies vegetais cultivadas na região em que você mora? Escolha um tipo de cultivo e avalie os pontos positivos (emprego, renda, alimentação, etc.) e impactos (poluição por agrotóxicos, desmatamento, etc.) a ele relacionados. Discuta com o produtor alternativas para diminuir os impactos."

Outro quadro que atinge diretamente o parâmetro buscado está intitulado de "Saiba Mais", e apresenta-se no final dos subcapítulos. Esse quadro traz várias referências bibliográficas e websites que permeiam o assunto tratado no capítulo, dando diretamente para o leitor outras sugestões de onde ele poderá encontrar informações sobre os temas abordados no livro.

O tema lobo-guará teve um resumo sobre, com foto e breve descrição, quando foi apresentado juntamente com, pelo menos, mais 15 animais. O parágrafo que aborda o loboguará está descrito a seguir:

O lobo-guará é um dos animais mais típicos. A cor laranja-avermelhada e o porte elegante fazem dele um dos animais brasileiros mais bonitos. Apesar do porte imponente, é muito tímido e inofensivo aos seres humanos, mantendo sempre uma certa distância de nós. É solitário e alimenta-se especialmente de vários tipos de frutos, como a lobeira e o araticum, e de pequenos animais, como insetos, roedores, tatus e perdizes. A lobeira ou fruta do lobo (Solanum lycocarpum) recebe esse nome justamente por ser um fruto bastante consumido pelo lobo-guará. Ele utiliza suas fezes e o odor de sua urina como sinais para informar sua presença a outros animais, delimitando assim, o território "dele". É bastante ativo, percorrendo longas distâncias em áreas abertas especialmente durante à noite. Infelizmente é um animal ameaçado de extinção. Durante suas longas caminhadas noturnas, comumente atravessa rodovias, onde, com frequência, são atropelados e mortos. Com as áreas protegidas são pequenas, o lobo-guará sai em busca de alimento em 
outros locais, chegando a eventualmente predar criações domésticas, como galinhas, sendo, por isso, perseguido pelos criadores dessas aves. Contudo, estudos recentes demonstram que o consumo de galinhas por lobos é muito reduzido. Outros animais da mesma família do lobo (canídeos) são o cachorro-do-mato, a raposa-do-campo e o cachorro-vinagre. (p. 31)

Todas as informações estão corretas, mas os conteúdos acerca do animal são muito abrangentes, e poderiam ser melhor explorados e relacionadas com o bioma. Dos canídeos sul-americanos, o lobo-guará é o maior, podendo chegar a 1,76 metros da ponta do fuço até a cauda, e possui em média $80 \mathrm{~cm}$ de altura de cernelha. O corpo é laranja-avermelhado, com uma crina e o fuço de cor preta, bem como as pernas longas, como se estivesse vestindo meias até metade das patas, que atuam facilitando o deslocamento pelo capim alto, e para os saltos no momento da caça; a ponta do rabo e interior das orelhas são brancas, estas que atuam como amplificadores de sons, também para caça (PAULA; GAMBARINI, 2013).

Amboni (2007) aponta que a lobeira (Solanum lycocarpum St.Hil.) é o principal item alimentar do lobo explicada pela sua disponibilidade ao longo do ano todo, além de ser vermífugo natural contra o nematóide Dioctophyme renale (Goeze, 1782) seguida pelos frutos Parinari obtusifolia, Allagoptera campestris e Cordiera cf. concolor (Cham. Kuntze), dentre outros, por isso, detentor do título de semeador do Cerrado. As presas mais encontradas são as aves (porém raramente galináceas), e pequenos mamíferos, sendo os mais representativos tatus, o roedor Necromys lasiurus (Lund, 1841), e o marsupial Gracilianus SP (Gardner e Creighton, 1989); também foram encontrados répteis, peixes e artrópodes, que apesar de frequentes foram pouco ingeridos, concluindo serem de menor importância na sua dieta generalista e onívora (DIETZ, 1984; BUENO et al, 2002; AMBONI, 2007).

O texto com relação ao animal também cita que ele delimita o seu território através das fezes, e do odor de sua urina, o que está correto, mas, mais uma vez, é uma informação que poderia ser melhor explorada. A espécie possui uma área de vida que varia de 20 a 115 $\mathrm{km}^{2}$, dependendo da qualidade do ambiente que abrange, disponibilidade de alimentos e outros recursos, e da composição da paisagem, sendo que a área pode sofrer $100 \%$ de sobreposição de espécimes de machos e fêmeas, mesmo que estes vivam isoladamente. Em uma noite (o lobo é um animal de hábitos noturnos) um lobo pode chegar a percorrer $30 \mathrm{~km}$, e utilizam marcação territorial através do odor, pela sua urina, e visual, pelas fezes depositadas em cima de cupinzeiros (PAULA et al., 2013; PAULA; GAMBARINI, 2013).

O lobo-guará pode se deparar com galinheiros durante suas andanças, chegando a predar galináceas, causando atrito com os criadores que matam os lobos, sendo uma das causas do seu declínio populacional. Porém, como dito anteriormente, análises da dieta 
encontram raramente em suas fezes vestígios de galinhas (menos de 1\%), ou seja, o lobo recebe a fama de predar animais domésticos sendo que nem sempre ele é responsável por isso (MORATÓ; 2001; MOTTA-JÚNIOR, 2003; PAULA; GAMBARINI, 2013), fator citado em todos os materiais didáticos analisados (citado no Livro Vivendo no Cerrado e Aprendendo com ele, p. 55).

Outro conflito entre guarás e humanos é devido a crendice. Retirar seu olho enquanto vivo, macerado e deixado imerso na água da chuva para ser bebido cura catarata; seu canino arrancado e pendurado no pescoço para evitar problemas dentários; pedaço de couro de lobo na sela do cavalo inibe problemas renais, e os protege contra bote de cobras; o fígado resulta em virilidade de quem o come. $\mathrm{O}$ uso de órgãos para cura é mito, mas essas práticas infelizmente ainda ocorrem pelo interior do nosso país, conferindo mais uma vertente preocupante na conservação dos lobos (PAULA; GAMBARINI, 2013), não sendo este fator abordado por nenhum material didático desenvolvido proposto pelo PAN-LG.

As ameaças primárias (mais relevantes) para o declínio populacional dos lobos-guará é, segundo análise do VORTEX, por atropelamentos, mas também pela perda de habitat (PAULA et al., 2009), e dados de 2004 revelam que mais da metade da área do Bioma Cerrado, "casa do lobo", foram transformados em pastagem devido à pecuária e ao plantio de soja, acelerando o processo de desmatamento e fragmentação (citado no Livro Vivendo no Cerrado e Aprendendo com ele, p. 50 e 57) (IBGE, 2004; MACHADO et al, 2004; KLINK; MOREIRA, 2005).

Com relação ao item “A importância ecológica do lobo guará foi descrita?”, não foram encontradas explicações diretas relacionadas ao lobo, mas esse tópico foi abordado diversas vezes ao longo do texto, deixando claro a importância que as espécies do Cerrado desempenham, como no quadro "E ainda..." (p.36).

\section{CONCLUSÃO}

Das quatro categorias de materiais propostos pelo PAN-LG (livro para ensino formal, livro infantil, cartilha, vídeo/DVD, jogo educativo), apenas duas foram realizadas (um livro para ensino formal e três vídeos).

Os vídeos abordam a região do estado de Minas Gerais onde se localiza o Parque Nacional da Serra da Canastra, importante área da qual é decorrente o lobo-guará, e a qual possui um dos mais importantes projetos de conservação dessa espécie. Não diminuindo sua 
importância, acredita-se que seria importante os materiais didáticos criados não se restringirem a apenas uma região, passando a falsa impressão de que a ocorrência do animal é apenas dessa localidade, ou de que apenas ela é importante, tendo em visto que pessoas leigas podem não conhecer o animal e não saber que eles estão inseridos próximas a elas. Consequência do foco dos materiais estarem voltados à Serra da Canastra, a ameaça mais bem explorada foi a da caça ao lobo devido aos conflitos com moradores rurais dessa área, sendo uma falha, pois outras ameaças são tão importantes quanto essa, levando a espécie ao declínio populacional, como atropelamentos, fragmentação de habitats para cultivo de soja e gado, e crendices/mitos sobre o animal possuir propriedades curativas. Outra crítica refere-se a não conclusão de todos os materiais propostos devido a falta de recursos financeiros, não cumprindo o proposto pelo PAN-LG, porém espera-se que estes iniciados sejam concluídos em breve, mesmo que o prazo de cinco anos para realização destes já tenha acabado.

Entretanto, todos os materiais foram bem classificados; os vídeos são facilmente encontrados na plataforma do YouTube, possuindo um grande número de visualizações, sendo que estas apenas aumentam com o passar do tempo, além de serem amplamente divulgados em outros meios digitais. $\mathrm{O}$ ponto positivo sobre abordarem a mesma região nos vídeos, é que os projetos desenvolvidos são sérios, são um sucesso, pois conseguem resultados na conservação tanto do lobo quanto, consequentemente, de outras espécies e do bioma Cerrado, e podem servir de exemplo e inspiração para que ações sejam investidas em outras áreas de ocorrências do animal. O livro, que recebeu classificação ótima, é utilizado no ensino formal em escolas, distribuído pelo Ministério da Educação, ou seja, também cumpre com seu objetivo de conscientização.

Espera-se que as pesquisas em conservação ambiental sejam instigadas, que haja investimentos no ecoturismo, incentivos econômicos para os produtores rurais na conservação da biodiversidade, que a produção e desenvolvimento de outros materiais didáticos sejam realizados, e outras ações de educação ambiental sejam feitas para minimização de conflitos entre as comunidades e o lobo-guará, um dos animais mais fantásticos do Brasil.

\section{REFERÊNCIAS}

AGUIAR, L. M. S.; MACHADO, R. B.; MARINHO-FILHO, J. A diversidade biológica do Cerrado. In: AGUIAR, L. M. de S.; A. C. (eds). Ecologia e caracterização do Cerrado, EMBRAPA Cerrado, Planaltina. p. 19-42. 2004. 
AMBONI, M. P. M. Dieta, disponibilidade alimentar e padrão de movimentação de loboguará Chrysocyon brachyurus, no Parque Nacional da Serra da Canastra, MG.

Dissertação de mestrado, Universidade Federal de Minas Gerais, Belo Horizonte, MG, 2007.

BIZERRIL, M. Vivendo no Cerrado e aprendendo com ele. 1.ed. São Paulo - Saraiva, 2009.

BRASIL. Portaria MMA n 42, de 31 de janeiro de 2014. Disponível em: http://cncflora.jbrj.gov.br/portal/static/pdf/portaria_MMA_43.2014.pdf. Acesso em: 30 de out. 2016.

BRASIL. Programa Nacional do Livro Didático (PNLD) 2016. Disponível em: http://portal.mec.gov.br/busca-geral/318-programas-e-acoes-1921564125/pnld439702797/12391-pnld. Acesso em: 01 nov. 2016.

BRESSAN, P. M.; KIERULFF, M. C. M.; SUGIEDA, A. M. Fauna Ameaçada de Extinção no Estado de São Paulo: Vertebrados. São Paulo: Fundação Parque Zoológico de São Paulo: Secretaria do Meio Ambiente, 2009.

BUENO, A. A., BELENTANI, S. C. S., MOTTA-JUNIOR, J. C. Feeding ecology of the maned Wolf, Chrysocyon brachiurus (Illiger, 1815) (Mammalia: Canidae), in the ecological station of Itirapina, São Paulo State, Brazil. Biota Neotropica v. 2, n. 2. ISSN 1676-0611. 2002.

DIETZ, J. M. Ecology and social organization of the Maned Wolf (Chrysocyon brachyurus), Smithsonian Contributions to Zoology 392:1-51. 1984.

FARIA, N. G.; SILVA, D. C. Legendas e janelas: questão de acessibilidade. Revista Sinalizar, v.1, n.1, p. 65-77; 2016.

GRANIZO, T. et al. Manual de Planejamento para a Conservação de Áreas, PCA. Quito: The Nature Conservancy e United States Agency Internacional Development. 205 p. 2006.

GARCIA, V. A. R. Informações sobre materiais didáticos [mensagem pessoal]. Mensagem recebida por<vivi.a.rachid@gmail.com> em 01 novembro de 2016.

GOMES, P. M.; MELO, C.; VALE, V. Santiago do. Avaliação dos impactos ambientais em nascentes na cidade de Uberlândia-MG: análise macroscópica. 2005. Uberlândia/MG,

Revista Sociedade e Natureza. Disponível em: www.seer.ufu.br/index.php/sociedadenatureza/article/viewFile/9169/5638. Acesso em: 25 out. 2016.

ICMBio, 2014. Disponível em: http://www.icmbio.gov.br/portal/especies-ameacadasdestaque. Acesso em: 01 nov. 2016.

IUCN Red List of Threatened Species. Disponível em: http://www.iucnredlist.org/. Acesso em 30 out. 2016.

KLINK, C. A.; MOREIRA, A. G. A conservação do Cerrado brasileiro. Belo Horizonte, Megadiversidade, v. 1, n. 1. p. 148-155. 2005. 
KRUGER, L. M.; ENSSLIN, S. R. Método Tradicional e Método Construtivista de Ensino no Processo de Aprendizagem. Revista Organizações em Contexto, vol. 9, n. 18, 52p. 2013. DOI: http://dx.doi.org/10.15603/1982-8756/roc.v9n18p219-27.

LIMA, E. C. A. et al. A importância da utilização de vídeos didáticos em educação ambiental. In: Congresso Norte e Nordeste de Pesquisa e Inovação (VII CONNEPI), VII., 2002. Palmas, Tocantins. Anais [...]. Palmas: [s.n.], 4 p. 2002. Disponível em: http://propi.ifto.edu.br/ocs/index.php/connepi/vii/paper/viewFile/4848/2785. Acesso em: 25 set. 2019.

MACHADO, R.B. et al. Estimativas de perda da área do Cerrado Brasileiro. Conservação Internacional, Brasília, Distrito Federal. 26 p. 2004.

MATTAR, J. Youtube na educação: o uso de vídeos em EAD. São Paulo: Universidade Anhembi Morumbi, 11 p. 2009.

MITTERMEIER, R. A.; GIL, P. R.; MITTERMEIER, C. G.. Megadiversidad - los países biológicamente más ricos del mundo. CEMEX: Mexico. 501 p. 1997.

MORATÓ, D. Q. Seletividade e sazonalidade das presas consumidas pelo lobo-guará (Chrysocyon brachyurus) no parque nacional da serra da Canastra, Minas Gerais. Orientador: José Carlos Motta Júnior. 2001. Tese (Doutorado em Ecologia) - Universidade de São Paulo, 2001.

MOTTA-JÚNIOR, J. C. et al. Fama injusta: novas informações sobre a dieta do lobo-guará. Ciência Hoje, São Paulo, v.31, n.185, p. 71-73. 2003.

PAULA, R. C. Informações sobre materiais didáticos [mensagem pessoal]. Mensagem recebida por <rogercunha@gmail.com> em 01 novembro de 2016.

PAULA, R. C.; GAMBARINI, A. Histórias de um lobo; Stories of a Golden Wolf. Avis Brasilis: Vinhedo, SP, 264 p. 2013.

PAULA, R. C.; MEDICI, P.; MORATO, R. G. Plano de Ação Nacional - Lobo Guará. Brasília/DF; IBAMA. 2009. Disponível em:

http://www.icmbio.gov.br/portal/faunabrasileira/plano-de-acao-nacional-lista/2120-plano-deacao-para-conservacao-do-lobo-guara. Acesso em: 25 out. 2016.

PAULA, R. C. et al. Avaliação do estado de conservação do Lobo-guará Chysocyon brachyurus (Illiger, 1815) no Brasil. Instituto Chico Mendes de conservação da Biodiversidade. 14 p. 2013.

PLANOS DE AÇÃO NACIONAL. Disponível em: http://www.icmbio.gov.br/portal/faunabrasileira/planos-de-acao-nacional?start=50. Acesso em: 25 out. 2016.

Vídeo: Programa para a Conservação do Lobo Guará-Lobos da Canastra. 2015. Disponível em: https://www.youtube.com/watch?v=JgUqBB0AUcw. Acesso em: 02 nov. 2016. 
Vídeo: Projeto Sou Amigo do Lobo. 2015. Disponível em:

https://www.youtube.com/watch?v=JgUqBB0AUcw. Acesso em: 25 out. 2016.

Vídeo: Conheça o lobo guará, símbolo do Cerrado. 2015. Disponível em

https://www.youtube.com/watch?v=CwIshsHrT04. Acesso em: 25 out. 2016.

SANTOS, S. S.; OLIVEIRA, S. S. DE. Análise de recursos visuais presentes em manuais didáticos a respeito do processo de respiração celular dos vegetais. 2012. Retirado do site:

http://www.uel.br/eventos/semanadaeducacao/pages/arquivos/anais/2012/anais/ensinofundam ental/analisederecursosvisuais.pdf. Acesso em: 25 nov. 2016.

SILVA, G. F.; RUSSO, S. L. Capacite: os caminhos para a inovação tecnológica. São Cristóvão: UFS. 180 p. 2014. DOI 10.7198/8-5782-24928-8-01.

VASCONCELOS, S. D.; SOUTO, E. O livro didático de ciências no Ensino Fundamental proposta de critérios para Análise do conteúdo zoológico. Pernambuco/Recife, Revista Ciência e Educação. 12 p. 2003. Disponível em: www.scielo.br/pdf/ciedu/v9n1/08.pdf. Acesso em: 25 out. 2016.

\section{DADOS DOS AUTORES}

\section{Samara Rached Souza}

E-mail: samyracheed@gmail.com

Currículo Lattes: http://lattes.cnpq.br/8081436009803501

Mestre profissional em Sustentabilidade na Gestão Ambiental pela Universidade Federal de São Carlos - Campus Sorocaba, UFSCAR, Brasil. Graduada em Ciências Biológicas Bacharel pela Universidade Federal de São Carlos - campus Sorocaba, UFSCAR, Brasil

\section{Simone Maria Ribeiro}

E-mail: simrbio@gmail.com

Currículo Lattes: http://lattes.cnpq.br/3109727842759309

Mestre profissional em Sustentabilidade na Gestão Ambiental pela Universidade Federal de São Carlos - Campus Sorocaba, UFSCAR, Brasil. Graduada em Ciências Biológicas Bacharel pela Universidade Paulista - campus Sorocaba, UNIP, Brasil.

\section{Rafael Ocanha Lorca Neto}

E-mail: rafael.ocanha@yahoo.com.br

Currículo Lattes: http://lattes.cnpq.br/3099157857752899

Mestre profissional em Sustentabilidade na Gestão Ambiental pela Universidade Federal de São Carlos - Campus Sorocaba, UFSCAR, Brasil. Graduado em Ciências Biológicas Bacharel pela Universidade Federal de São Carlos - campus Sorocaba, UFSCAR, Brasil.

\section{Sílvio César Moral Marques}

E-mail: silvioccmm@gmail.com

Currículo Lattes: http://lattes.cnpq.br/6047434055828372

Pós-Doc pela Universidad Nacional Autónoma de Mexico, UNAM, México. Doutor em Filosofia pela Universidade de São Paulo, USP, Brasil. Mestre em Filosofia pela Pontifícia 
Universidade Católica de Campinas, PUC Campinas, Brasil. Especialista em Filosofia Ética e graduado em Filosofia e Administração pela Pontifícia Universidade Católica de Campinas, PUC Campinas, Brasil.

\section{Ismail Barra Nova Melo}

E-mail: ismail@ufscar.br

Currículo Lattes: http://lattes.cnpq.br/3576937472687059

Doutor e mestre em Geografia pela Universidade Estadual Paulista Júlio de Mesquita Filho (UNESP), Brasil. Especialista em Metodologia e Didática do Ensino Superior e Bacharel em Estudos Sociais Licenciatura Plena em Geografia pela Faculdade de Educação São Luís (FESL), Brasil. 